Andrews University

Digital Commons @ Andrews University

1972

\title{
The Relationship Between Athletic Success and Scholastic Achievement
}

Norman Bruce Province

Andrews University

Follow this and additional works at: https://digitalcommons.andrews.edu/theses

Part of the Secondary Education Commons

\section{Recommended Citation}

Province, Norman Bruce, "The Relationship Between Athletic Success and Scholastic Achievement"

(1972). Master's Theses. 151.

https://dx.doi.org/10.32597/theses/151

https://digitalcommons.andrews.edu/theses/151

This Thesis is brought to you for free and open access by the Graduate Research at Digital Commons @ Andrews University. It has been accepted for inclusion in Master's Theses by an authorized administrator of Digital Commons @ Andrews University. For more information, please contact repository@andrews.edu. 


\author{
ABSTRACT OF GRADUATE STUDENT RESEARCH \\ Thes is \\ Andrews University \\ Department of Education
}

Title: The Relationship Between Athletic Success and Scholastic

Achievement

Name of researcher: Norman Bruce Province

Name of faculty advisers: Dr: Conrad A. Reichert, Chairman

Dr. Wilfred W. Liske

Dr. Wilfred G. A. Futcher

Date completed: August 1972

Recently the Berrien Springs Senior High School Board members voted to transfer from one interscholastic athletic league to another, since the high school's football and basketball teams had been having very poor athletic success. The faculty and administration felt that always losing was having a demoralizing effect on the entire school body, which was carrying over into their academic success.

This study covered a twenty year period running from 1953 to 1972 at the Berrien Springs Senior High School. The purpose was to see if the interscholastic athletic success in varsity and junior varsity football and basketball during this period was (1) significantly correlated with the academic success of the athletes, and (2) significantly correlated with the academic success of the non-athletes. The Pearson product- 
moment correlation coefficient was used to measure the possible correlation.

It was hypothesized that (A) among athletes there is a positive correlation between athletic success and academic success, (B) among nonathletes there is a positive correlation between athletic success and academic success, (C) among non-athletes the higher the grade level the greater the correlation between athletic success and academic success, and (D) among non-athletes the correlation between athletic success and academic success is greater for males than for females.

Hypothesis A was not supported when the total athletic success of the school was examined. However, when only the athletic success of varsity football was examined, the correlation between athletic and academic success was positive and statistically significant.

Hypothesis $B$ was not supported when all non-athletes were considered. When they vere divided into male and female groups in each grade level, nine male and one female correlations were statistically significant, but only one was positive.

Hypothesis $\mathrm{C}$ was not supported. However, negative correlations between male academic success and varsity football success did reach significance.

Hypothesis D was not supported. Among males most correlations were negative, and among females the majority were positive, but only one of these coefficients was statistically significant.

It was concluded that interscholastic athletic competition probably cannot be condemned or merited because of a possible relationship between athletic success and academic success. 
Andrews University

School of Graduate Studies

THE RELATIONSHIP BETWEEN ATHLETIC

SUCCESS AND SCHOLASTIC

ACHIEVEMENT

A Thesis

Presented in Partial Fulfillment

of the Requirements for the Degree

Master of Arts

by

Norman Bruce Province

August 1972

Approval

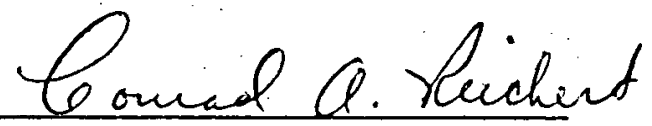



TABLE OF CONTENTS

Chapter

Page

I. INTRODUCTION . . . . . . . . . . . . . . . . . . . . 1

Statement of the problem . . . . . . . . . . . . . . . . 1

Purpose of the study . . . . . . . . . . . . . . . 1

II. REVIEW OF THE LITERATURE . . . . . . . . . . . . . . 3

Related research .................... 3

Rationale underlying the present study . . . . . . . 6

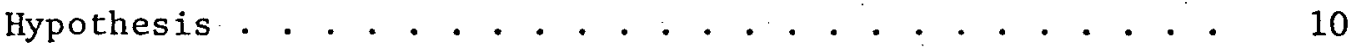

III. METHODOLOGY . . . . . . . . . . . . . . . . . 12

Variables . . . . . . . . . . . . . . 12

Definitions ................... 13

Population . . . . . . . . . . . . . . . . 13

Statistics.................. 14

Procedure ..................... 15

IV. ANALYSIS OF DATA...................... 16

Hypothesis A: Among athletes there is a positive correlation between athletic success and academic success. .

Hypothesis B: Among non-athletes there is a positive correlation between athletic success and academic success . . . . . . . . . . . . . . . . . .

Hypothesis C: Among non-athletes the higher the grade level the greater the correlation between athletic success and academic success . . . . . . . . . .

Hypothesis D: Among non-athletes the correlation between athletic success and academic success is greater for males than for females . . . . . . . . . . . . . . 
V. SUMMARY AND CONCLUSIONS . . . . . . . . . . . . . . 28

Summary of data................. . . 28

Conclusions . . . . . . . . . . . . . . . 30

Implications . . . . . . . . . . . . . . . 31

BIBLIOGRAPHY . . . . . . . . . . . . . . . . . . . . . 33 


\section{LIST OF TABLES}

Table

1. Correlation Between Athletic Success and Academic Success of Athletes . . . . . . . . . . . . . . . . . . .

2. Correlation Between Athletic Success and Academic Success of Al1 Non-athletes... . . . . . . . . . . . . . .

3. Correlation Between Athletic Success and Academic Success of All Non-athletes by Grade Level . . . . . . . . . . . 21

4. Correlation Between Athletic Success and Academic Success of All Male and Female Non-athletes . . . . . . . . . . .

5. Correlation Between Athletic Success and Academic Success of All Male Non-athletes by Grade Level . . . . . . . . . . . 24

6. Correlation Between Athletic Success and Academic Success of Al1 Females by Gradé Level 


\section{CHAPTER I}

\section{INTRODUCTION}

\section{Statement of the Problem}

In a recent board meeting the Berrien Springs Senior High School board members voted to transfer from one interscholastic athletic league to another. Berrien Springs had previously belonged to the Blossomland Conference which included seven other schools in the area. Compared with the other schools in the league, Berrien Springs was the smallest and was having very poor league success. It was felt that because it was the smallest school it naturally had a smaller population of high performing athletes.

The faculty and administration felt that always losing was having a demoralizing effect on the entire school body, which was carrying over into their academic progress.

At the time of the board meeting another interscholastic league in the area had an opening for a team. This league was composed of smaller schools--more the size of Berrien Springs--and it was the consensus of the faculty and administration that changing to this league would result in more wins which would in turn increase school morale and academic progress.

\section{Purpose of the Study}

The purpose of this study was to see if the interscholastic athletic success in varsity and junior varsity football and basketball was 
(1) significantly correlated with the academic success of the athletes, and (2) significantly correlated with the academic success of the nonathletes.

The finding of a correlation between athletic success and the academic success of the athletes would suggest possibly that an interscholastic athletic success expectancy was transferring to academic success.

The finding of a correlation between athletic success and the academic success of the non-athletes would indicate that athletic success expectancy was generalizing to the non-athletes and transferring to their success expectancy in academic achievement.

In the U. S. A., everyone is guaranteed by the constitution to have an equal chance in education. If a high correlation is found, this would indicate that success or lack of success in interscholastic sports could possibly be the cause of an inequity in the quality of learning that is taking place in our schools. 
CHAPTER II

REVIEW OF THE LITERATURE

\section{Related Research}

In all human societies, rituals, festivals, dances, music, sports, and games not only give pleasure but also provide outlets for creativity and reinforce group identity (Kessing, 1941). The cultural role of sports in our society has been little understood. In American culture the emphasis has been on work, not on play. Recreation in our early history was rationalized in work terms such as--barn-raisings, housewarmings, and corn husking contests. Even the pleasures of hunting and fishing were rationalized as contributing to the food supply.

In present day American culture a profound cultural change has taken place with regard to the role of sports and physical recreation. Men and women go forth with golf clubs, tennis rackets, fishing reels, skis, or what-have-you for no other reason than the pursuit of pleasure (Cozens and Stumpf, 1953). This change in our culture seems to be the result of a shift in our objectives and goals; a shift from an era when character was formed for work, to an era where character is increasingly formed for leisure (Reisman, Glazer, and Denny, 1950).

Many public schools participate in a large interscholastic sport program assuming that this participation has a positive effect on physical and psychological development: Two major arguments have been presented for the participation in sports: (1) the participation in sports 
makes a positive effect on the development of emotional health, (2) sports are a form of social organization that help to control undesirable aggressive behavior by providing a cathartic discharge of aggression. Those who argue that sports help to develop emotional health make many statements in support of this idea. These are summarized by Layman (1970), in the form of six propositions:

Proposition One: Engaging in sports promotes physical fitness; physical fitness is associated with good emotional health and a lack of fitness with poor emotional health.

Proposition Two: The acquisition of the motor skills involved in sports contributes toward meeting the basic needs of safety and esteem in young children of both sexes and in boys and young men from the early grades through college years.

Proposition Three: Supervised play presents potentialities for promoting emotional health and preventing delinquency. Proposition Four: Clinical evidence from play therapy, group therapy, and the use of physical exercise as a adjunct in the treatment of emotionally-ill patients indicates that when play, recreation and athletic activities are planned with individual needs in mind, they may be a very valuable means of improving emotional health.

Proposition Five: Play and sports supply outlets for the expression of emotions, and outward expression of emotion in approved activities is conducive to the development and maintenance of emotional health.

Proposition Six: Competitive sports, if properly used, may enhance emotional health and the acquisition of desirable personality traits (pp. 250-225).

In criticism of these propositions, sports are conducive to emotional health if they promote physical fitness, but not all sports promote physical fitness. They encourage healthy emotional development if the participant has enough skill to merit the approval of his peers and significant others, but not all participants will have such skills. . They encourage emotional health if the participant can use sports to express feeling, but not all participants have emotional experiences of this type.

Sports have been described as the teaching and enforcement of a verbal code of behavior relating to fighting (Scott, 1958). Because 
sports are a form of social organization, it is believed that they help to control undesirable aggressive behavior by providing a cathartic discharge of aggression.

On the hypothesis that there is some sort of cumulative drive toward aggressive behavior, it would follow that persons who express violence should get rid of their feelings and be more peaceful for some time afterwards. From this reasoning has come the catharsis hypothesis. According to the catharsis hypothesis, the aggressive act releases pentup energy, reduces tension, makes the individual feel better, and decreases the remaining motivation for aggressive behavior. However; experiments done along this 1 ine have not supported this hypothesis.

Berkowitz (1964) found that children who became angry and were allowed to express their anger did not become more peaceful, but actually learned to be aggressive. He found that every time aggression was expressed it helped to form a stronger habit towards aggressive behavior. Feshbach (1956) also did not find a cathartic reduction in aggression as the result of play therapy. In his study the experimental group was given toys which would lead to aggressive play: soldiers, pirates, cowboys, and Indians. The control group played with neutral toys such as trains, circuses, farms, and storybooks. It was found that the experimental group manifested significantly more aggression than did the control group during the play sessions, and that neither group showed any significant change in classroom aggression after the cathartic play sessions.

In an interesting study by Kenny (1953), an experimental group of fifteen first-grade children had two play-therapy sessions, in which they engaged in hitting, attacking, and verbally attacking dolls. A 
control group spent equal time playing on swings or with a jigsaw puzzle. Using a sentence completion test as a measure of aggression, the control group was found to have no change in aggression from pre-catharsis to post catharsis testing.

Stone (1950) administered the TAT to college varsity football players before and after scrimmage and after the football season. Their responses were compared to the stories told by matched controls. There was no difference between the two groups in fantasy aggression resulting from scrimmage, but the football players showed less aggression at the end of the season. There was some question as to whether the reduction in aggression in the football players at the end of the season was due to the cathartic discharge of aggression or to feelings of guilt when positive reinforcement no longer occurred.

To summarize, Berkowitz (1962) says,

Most disturbed persons do not seem to have either (a) weaker aggressive inclinations or (b) less concern about their hostile tendencies after engaging in socially sanctioned aggressive sports. If hostile behaviors are less apparent following such competitive activities, . . ., these actions may have been inhibited by gameinduced guilt or anxiety (p. 207).

\section{Rationale Underlying the Present Study}

The theoretical base for the present study was found in J. B. Rotter's theory of social learning, and from reviewing studies done comparing athletic participation and academic performance.

A survey of the literature relating athletic participation to academic performance revealed that there were about as many authors who concluded that athletes were academically superior to non-athletes, as there were those who believed there was no difference, or that nonathletes were superior (Kyle, 1941). In other words it was found that 
athletes and non-athletes performed equally well academically.

Since 1940, similar studies have come to the same conclusion. Kremer (1942) sampled 219 athletes and 184 non-athletes in six high schools in Monroe County, Michigan. He found that athletes' academic performance was higher than that of non-athletes by over one third of a letter grade, but he concluded that this difference was not significant. In a study at the University of Kansas comparing college athletes with non-athletes, no difference was found in academic performance (Summers, 1945). More recently, Belk (1955), Ferguson (1955), and Jordon (1955), have come to similar conclusions.

In these research studies no mention was made of the athletic performance. These studies leave out a very important variable-the success of the team. They did not compare athletic performance with academic performance. Of all the studies compiled by Kyle, it would seem logical that about one-half of the schools would have losing records. Comparing this with his findings it would seem possible that it was the success of the participation rather than the participation itself that caused the change in scholastic achievement.

Experimentally induced success or failure experiences can have consistent and reliable effects on children's performance predictions. Success experiences lead to a raising of performance estimates, while failure experiences lead to a lowering of the performance predictions. (Schuster, 1971)

The social learning theory of Rotter (1954) postulates that behavior is determined partially by the individual's expectancy that reinforcement will occur. This expectancy is a function of the schedule of reinforcement in the specific situation and of the generalized ex- 
pectancy developed from other situations and generalized to the present situation.

Kyle (1941) found that fifty percent of the authors reported that athletes performed better academically than non-athletes, and fifty percent of the authors reported that athletes were inferior to non-athletes. In athletic competition a team either wins, loses, or ties. In league athletic competition the mean score is always one-half the number of games played--the total number of games won in the league is equal to the total number of games lost. Applying Rotter's postulate to this learning situation one would expect a successful athlete or team of athletes to generalize their success expectancy to other areas of behavior. If this indeed did happen it would be expected that about one-half of the studies would reveal athletes to be superior to non-athletes academically and one-half would reveal athletes to be inferior academically simply because one-half of the schools would have a winning record, and one-half of the schools would have a losing record during any one year. The failure expectancy of the half that lost athletically could have been transferred to academic areas causing a lower GPA, and the success expectancy of the half that won athletically could have been transferred to academic areas causing a higher GPA.

Examining more closely the generalization of expectancy, it has been found that generalization depends on the similarity of reinforcement, and on how much the given reinforcement or goal is valued by the individual relative to other goals available to him in the situation.

Crandal1 (1951) demonstrated that induced failure on a physical skills task influehced TAT stories told after the failure experience. The greatest effect was found in stories involving physical skill ac- 
tivities, the next greatest in stories involving academic accomplishment, and the least effect in stories involving relationships with opposite sex peers.

Jessor (1954), demonstrated that induced failure on an arithmetic task reduced the individual's stated expectancies regarding performances on a vocabulary task, a motor task, and a social skills task.

Chance (1959) found that expectancies would generalize to a greater extent in situations where subjects saw two behaviors as leading to the same goal as contrasted with situations in which the two behaviors were seen as leading to different goals. A second hypothesis that stated that generalization would be greater as the difference between the expected and obtained score was greater was also supported by his research. The findings of Crandall, Jessor, and Chance all support Rotter's theory of social learning, which in turn supports the hypothes is that athletic success expectancy could affect academic success expectancy. Cranda11; in addition to supporting Rotter's theory, found that the greatest success expectancy was in physical skill activity stories.

Chance also found that expectancies would generalize to a greater extent in situations where there was a common reinforcer. In the present study a common reinforcement for both athletic and academic success exists in peer and parental approval, so according to Chance we would expect a high probability of generalization of success from the athletic situation to the academic situation.

No research was found examining the possibility of the transfer of generalization of expectancy from one person to another. If a correlation is found between athletic success and the academic success of nonathletes, this proposition could be a possibility. In our public schools 
great effort is made to get the whole school to participate in pep rallies, bands, cheer leading, etc. The success-failure experiences of the school in team interscholastic sports could thus affect the academic success of non-athletes.

In the present study the possibility of a correlation between athletic success and academic success of athletes and non-athletes was examined. Whether academic success causes athletic success, or athletic success causes academic success, or whether some third variable causes both was not determined by this study. A sizable correlation would indicate that the existence of a causative relationship between the two was possible and that further study should be undertaken. A low correlation would indicate that the chance of academic success influencing athletic success or vice-versa was probably sma11.

There are other variables besides athletic success that could correlate with scholastic achievement. One might be the personality of the principal, another the enthusiasm of the staff. Variables such as these are nearly impossible to control; but, by studying the relationship between athletic success and academic achievement across a period of twenty years these random effects are attenuated.

\section{Hypothes is}

The preceding rationale leads to the following hypotheses.

Hypothesis A.

Among athletes there is a positive correlation between athletic success and academic success.

Hypothes is B.

Among non-athletes there is a positive correlation between ath- 
letic success and academic success.

Hypothesis C.

Among non-athletes the higher the grade level the greater the correlation between athletic success and academic success.

Hypothes is D.

Among non-athletes the correlation between athletic success and academic success is greater for males than for females. 


\section{CHAPTER III}

\section{METHODOLOGY}

$\underline{\text { Variab1es }}$

Two variables were considered in this study, (1) athletic success, and (2) academic success.

Athletic success was analyzed within five groups over a twenty year period. These groups were composed of the subjects who played, (1) varsity football, (2) varsity basketball, (3) junior varsity footba11, (4) junior varsity basketball, and (5) those who were athletes in any of the four preceding groups.

Academic success was analyzed within two major groups, (1) athletes, and (2) non-athletes. The group of non-athletes was considered as anyone who did not play in one or more of the five team groups mentioned above.

The academic success of the athletes was analyzed for the five team groups mentioned above during the same twenty year period for, (1) the first semester of each year, (2) the second semester of each year, and (3) the combined first and second semesters of each year.

The academic success of the non-athletes was also analyzed during the same twenty year period for, (1) the first semester of each year, (2) the second semester of each year, and (3) the combined first and second semesters of each year. Non-athletes were considered separately as (1) a whole group, (2) as a group of males, (3) as a group of females, 
(4) as different groups of ninth, tenth, eleventh, and twelfth grade levels, and (5) as boy and girl groups within each grade level.

\section{Definitions}

Athletic success was determined by dividing the number of interscholastic games won by the number of these games played during each year of a twenty year period running from the 1952-53 school year through the 1971-72 school year. This number, $\frac{\text { games won }}{\text { total games played }}$ (abbreviated AtS,) is defined as the coefficient of athletic success and was calculated for each of the five athletic groups. During the twenty year period junior varsity football was not played one year. The footba1l athletic season ran from September 19 through November 7 each year. The basketball athletic season ran from December 5 through February 28.

The academic success of each group was considered as the GPA (grade point average) earned during the first semester, second semester, and yearly. These group GPA's were obtained by dividing the total number of honor points by the total number of credit units taken by each group. The honor point system used was as follows: $A=4, B=3, C=2$, $\mathrm{D}=1$, and $\mathrm{F}=0$ honor points.

The following categories were considered as academic: English, foreign languages, mathematics, science, and social studies.

\section{Population}

The population under study was all students attending the Berrien Springs Senior High School in Berrien Springs, Michigan; during the 1952-53 school year through the 1971-72 school year. Students who did not attend for at least one full year were not included. The size of the school population ranged from 200 to 500 students across this twenty 
year period. Berrien Springs is located in a rural-agricultural section of southwestern lower Michigan, about ninety miles from Chicago, Illinois. The majority of the students came from working class families who were employed as farmers or in industries in the surrounding communities of Buchanan, Saint Joseph, Niles, and Benton Harbor.

\section{$\underline{\text { Statistics }}$}

The Pearson product-moment correlation coefficient was used to determine the extent to which variations in interscholastic athletic success were related to variations in GPA. The data covered twenty successive years for varsity football, varsity basketba11, and junior varsity basketball; and nineteen successive years for junior varsity footbal1. In each correlation the pairs of GPA-AtS's were correlated as follows:

$\begin{array}{ccc}\text { Correlation of Varsity } & \text { Footbal1 } \\ \text { Athlete GPA-first semester } & \\ \text { Year } & \text { Ats } & \text { GPA } \\ & & \\ 52-53 & 1.000 & 2.557 \\ 53-54 & 0.800 & 2.803 \\ 54-55 & 0.750 & 2.560 \\ 55-56 & 1.000 & 2.573 \\ 56-57 & 0.875 & 2.769 \\ 57-58 & 0.714 & 2.481 \\ 58-59 & 0.571 & 2.390 \\ 59-60 & 0.500 & 2.032 \\ 60-61 & 0.250 & 2.507 \\ 61-62 & 0.500 & 2.357 \\ 62-63 & 0.375 & 2.376 \\ 63-64 & 0.571 & 2.291 \\ 64-65 & 0.286 & 2.050 \\ 65-66 & 0.375 & 2.476 \\ 66-67 & 0.125 & 2.176 \\ 67-68 & 0.375 & 2.526 \\ 68-69 & 0.625 & 2.326 \\ 69-70 & 0.250 & 2.068 \\ 70-71 & 0.250 & 2.565 \\ & & \\ \text { P = } 0.6698 & \mathrm{p} & .01\end{array}$


A total of 240 correlation coefficients were calculated. Of these, fifteen involved athletes and 225 involved non-athletes. The fifteen athlete correlations included all permutations of the five groups of team scores and the three groups of GPA's. The 225 non-athlete correlations included all permutations of the five groups of team scores, the five grade levels (ninth, tenth, eleventh, twelfth, and all grades combined), the three sex groups (males, females, and males and females combined), and the three groups of GPA's (first, second, and both semesters combined).

\section{Procedure}

Data for student GPA was obtained from the student files. This data was sorted into the categories being correlated. The data for athletic success was obtained from the school annual--Canoe. From the categorized data, mean GPA's and AtS's were calculated. From these pairs of data the Pearson product-moment correlation coefficient was calculated by a. computer. The coefficients were then tested for significance using the two-tallied test. For $18 \mathrm{df} .444$ or .561 was needed for significance at the .05 or .01 levels of significance, and for $17 \mathrm{df} .456$ or .576 was needed for significance at the .05 or .01 levels of significance. 
CHAPTER IV

\section{ANALYSIS OF DATA}

To test each of the following hypotheses the Pearson productmoment correlation coefficient was calculated between academic success and athletic success for the relevant group and period. The following abbreviations were used: Total AtS = the combined athletic success, $\mathrm{VF}=$ varsity football success, $\mathrm{VB}=$ varsity basketball success, $\mathrm{JVF}=$ junior varsity football success, JVB = junior varsity basketball success. In each correlation $N$ equaled twenty with the exception of those involving junior varsity football where $\mathrm{N}$ equaled nineteen. First, second, and both semester GPA's were calculated because of an overlap between the basketbal1 seasons and first and second semesters (approximately the first half of the basketball season was played during the first semester, and the rest was played during second semester), and because of the possibility that the success expectancy obtained in football during the first semester carried over into the second semester.

\section{Hypothesis A. Among athletes there is a positive correlation}

\section{between athletic success and academic success}

As a logical deduction from Kiles thesis and because of Rotter's postulate in social learning theory, one would expect the athletic success of sport participants to be positively correlated with their academic success. Table 1 contains the data to which this hypothesis refers. 
TABLE 1

CORRELATION BETNEEN ATHLETIC SUCCESS

AND ACADEMIC SUCCESS

OF ATHLETES

\begin{tabular}{|c|c|c|c|}
\hline \multirow{2}{*}{ Ats } & \multicolumn{3}{|c|}{ GPA per semester } \\
\cline { 2 - 4 } & $1 \mathrm{st}$ & 2nd & both \\
\hline Tota1 AtS & 0.2535 & 0.1730 & 0.2223 \\
$\mathrm{NFF}$ & $0.6698 * *$ & $0.6316 * *$ & $0.6517 * *$ \\
$\mathrm{VB}$ & 0.1507 & 0.0926 & 0.1388 \\
$\mathrm{JVF}$ & -.0994 & -.2693 & -.0719 \\
$\mathrm{JVB}$ & 0.0153 & -.2617 & -.0090 \\
\hline
\end{tabular}

$* x p .01$

The correlations for the total athletic success of the athletes did not reach significance. However, they were all positive which suggests that a relationship in accordance with Hypothesis A possibly exists.

When the athletic success was broken down into the success of each team the success in varsity football is significantly correlated with academic success during both semesters. The highest correlation was during the first semester. This was expected because varsity football was played only during the first semester. The significant correlation during the second semester could possibly indicate that the success expectancy obtained from varsity football carried over into second semester affecting second semester academic success expectancy. Another very logical possibility is also suggested by Hypothesis A--academic success 
could affect athletic success. If a third variable such as intelligence was affecting both academic success and athletic success, more intelligent athletes would be expected to continue performing better academical1y during the second semester.

Examining the rest of the correlations in Table 1, none of these possibilities seem to be supported. In both of the junior varsity groups some negative correlations were even found, but these are not significantly different from zero. Speculating, negative correlations between the academic and athletic success of the athletes could be the result of spending more time athletically at the expense of academics during a successful year, and less time during an unsuccessful year.

\section{Hypothesis B: Among non-athletes there is a positive correlation}

\section{between athletic success and academic success}

This hypothesis examines the possibility that athletic success could influence the success expectancies of non-athletes (non-participants in the interscholastic team competition). In public schools so much emphasis is placed on interscholastic team success, that the competition becomes a school effort, rather than just a team effort. The success expectancy from winning or losing is thus not only a team expectancy, but it could also possibly become a school expectancy.

The data in Table 2, however, does not support this hypothesis.

These correlations do not reach significance. This suggests that the success of the school athletically is not related to the academic success of the non-athletes.

The correlafions that approach significance are again between varsity football success and academic success. However, these are all negative correlations, as are eleven of the fifteen correlations. Again 
TABLE 2

CORRELATION BETWEEN ATHLETIC SUCCESS

AND ACADEMIC SUCCESS OF

ALL NON-ATHLETES

\begin{tabular}{|c|c|c|c|}
\hline \multirow{2}{*}{ AtS } & \multicolumn{3}{|c|}{ GPA per semester } \\
\cline { 2 - 4 } Total AtS & 1st & 2nd & both \\
\hline & -.1080 & -.0917 & -.1015 \\
VF & -.3223 & -.2428 & -.3046 \\
VB & -.0192 & -.0825 & -.0521 \\
JVF & 0.0252 & 0.1252 & 0.0652 \\
JVB & 0.0798 & -.1292 & -.1199 \\
\hline
\end{tabular}

speculating, negative correlations could be the result of spending more time engaging in athletically orientated behavior during athletically successful years, and less time during athletically unsuccessful years.

Hypothesis C: Among non-athletes the higher the grade level the greater the correlation between athletic success and academic success

Varsity teams are composed of the best athletes in the school. These are naturally the older and stronger students. The success of these athletes determines the athletic image of the school, therefore students in higher grade levels feel more responsible for performing successfully in athletics. Upper grade non-athletes could possibly bear more of the guilt for lack of success or feel more a part of the reason for success in athletics because they were part of the same group that the athletes were chosen from. 
The younger students, that is, those in the ninth and tenth grade levels, do not bear this responsibility. Most of the athletes in this group play in the junior varsity leagues. These are the proving grounds where the future varsity players are chosen. This league is similar to the "minor league" in professional baseba11. Non-athletes in this grade level are probably not as concerned about athletic success as those in higher grade levels.

It thus seems possible that the success expectancy generalization from athletic success to academic success for non-athletes would be higher for the upper grade levels. Data relevant to this hypothesis is found in Table 3.

Again; no significant correlations are found, and there are a number of negative correlations.

There is, however, a trend from ninth through eleventh grade for negative correlations. There is then an abrupt change in the twelfth grade to a positive correlation. This could indicate a change in the direction of the hypothesis at this grade level. Speculating, the athletically orientated behavior in grades nine through eleven could possibly be increasingly taking time from academic behavior. If this happened, more time spent in athletically orientated behavior during winning years could cause a decrease in academic success during these years or vice-versa. In the twelfth grade it appears that athletic success expectancy over-rides the negative effect of time. Surprisingly the most positive correlation found was between academic success and junior varsity success. Perhaps twelfth grade non-athletes feel more responsible for the younger athletes. This discussion is very tentative as the correlation coefficients are not statistically significant. 
TABLE 3

CORRELATION BETWEEN ATHLETIC SUCCESS AND ACADEMIC

SUCCESS OF ALL NON-ATHLETES BY GRADE LEVEL

\begin{tabular}{|c|c|c|c|c|}
\hline \multirow{2}{*}{ Ats } & \multirow{2}{*}{ Grade } & \multicolumn{3}{|c|}{ GPA per semester } \\
\hline & & Ist & 2nd & both \\
\hline Total Ats & $\begin{array}{r}9 \\
10 \\
11 \\
12\end{array}$ & $\begin{array}{r}0.1280 \\
-.1744 \\
-.2682 \\
0.1244\end{array}$ & $\begin{array}{r}-.0501 \\
-.1069 \\
-.1493 \\
0.1959\end{array}$ & $\begin{array}{r}0.0523 \\
-.1473 \\
-.2213 \\
0.1910\end{array}$ \\
\hline VF & $\begin{array}{r}9 \\
10 \\
11 \\
12\end{array}$ & $\begin{array}{l}-.3284 \\
-.2242 \\
-.3373 \\
0.0000\end{array}$ & $\begin{array}{r}-.2183 \\
-.1284 \\
-.3508 \\
0.2368\end{array}$ & $\begin{array}{r}-.2419 \\
-.2092 \\
-.3412 \\
0.1565\end{array}$ \\
\hline VB & $\begin{array}{r}9 \\
10 \\
11 \\
12\end{array}$ & $\begin{array}{r}0.3226 \\
-.1645 \\
-.4174 \\
0.1078\end{array}$ & $\begin{array}{l}-.0116 \\
-.0696 \\
-.1115 \\
0.1959\end{array}$ & $\begin{array}{r}0.1543 \\
-.1429 \\
-.2837 \\
0.1910\end{array}$ \\
\hline JVF & $\begin{array}{r}9 \\
10 \\
11 \\
12\end{array}$ & $\begin{array}{l}0.1259 \\
-.1511 \\
0.0528 \\
0.1726\end{array}$ & $\begin{array}{l}0.1671 \\
0.1372 \\
-.0556 \\
0.3688\end{array}$ & $\begin{array}{r}0.1381 \\
-.0180 \\
-.0045 \\
0.3505\end{array}$ \\
\hline JVB & $\begin{array}{r}9 \\
10 \\
11 \\
12\end{array}$ & $\begin{array}{r}0.2586 \\
-.1647 \\
-.2835 \\
0.2967\end{array}$ & $\begin{array}{l}-.0928 \\
-.1484 \\
-.0775 \\
-.0481\end{array}$ & $\begin{array}{r}0.0444 \\
-.1523 \\
-.2051 \\
0.1207\end{array}$ \\
\hline
\end{tabular}


Hypothesis D. Among non-athletes the correlation between athletic success and academic success is greater for

males than for females

Al1 of the teams considered were male teams. It would thus seem logical that the athletic success expectancy would generalize more to male non-athletes than to females. Table 4 contains the correlations between the academic success and the athletic success of females and nonathlete males.

TABLE 4

CORRELATION BETWEEN ATHLETIC SUCCESS AND ACADEMIC SUCCESS

OF ALL MALE AND FEMALE· NON-ATHLETES

\begin{tabular}{|c|c|c|c|c|}
\hline \multirow{2}{*}{ Ats } & \multirow{2}{*}{ sex } & \multicolumn{3}{|c|}{ GPA per semester } \\
\hline & & Ist & 2nd & both \\
\hline Total AtS & $\begin{array}{l}\text { M } \\
\text { F }\end{array}$ & $\begin{array}{r}-.2405 \\
0.1829\end{array}$ & $\begin{array}{r}-.2119 \\
0.1029\end{array}$ & $\begin{array}{r}-.2375 \\
0.1553\end{array}$ \\
\hline VF & $\begin{array}{l}\mathrm{M} \\
\mathrm{F}\end{array}$ & $\begin{array}{l}-.4760 \% \\
0.1459\end{array}$ & $\begin{array}{r}-.3137 \\
0.1454\end{array}$ & $\begin{array}{r}-.4111 \\
0.1457\end{array}$ \\
\hline VB & $\begin{array}{l}\mathrm{M} \\
\mathrm{F}\end{array}$ & $\begin{array}{r}0.0720 \\
-.1167\end{array}$ & $\begin{array}{l}-.0218 \\
-.01194\end{array}$ & $\begin{array}{r}0.0105 \\
-.1169\end{array}$ \\
\hline JVF & $\begin{array}{l}M \\
F\end{array}$ & $\begin{array}{l}-.2551 \\
0.2191\end{array}$ & $\begin{array}{l}0.0292 \\
0.3316\end{array}$ & $\begin{array}{l}-.1070 \\
0.2490\end{array}$ \\
\hline JVB & $\begin{array}{l}\mathrm{M} \\
\mathrm{F}\end{array}$ & $\begin{array}{r}-.2315 \\
0.2489\end{array}$ & $\begin{array}{l}-.2141 \\
-.1192\end{array}$ & $\begin{array}{r}-.2205 \\
0.0879\end{array}$ \\
\hline
\end{tabular}

$\therefore \quad * p<.05$ 
Examining the correlation coefficients for males, the only statistically significant coefficient is between male non-athlete academic success and first semester varsity football success. Again, surprisingly, this correlation is negative. The correlations between academic success and total athletic success are all negative.

Examining the correlations between the academic success of girls and the total athletic success, all of the correlations are positive. When broken into football and basketball, the athletic success in footbal1 is positively correlated with academic success, whereas the athletic success in basketball is predominately negatively correlated.

It will be remembered that a trend of increasingly negative correlations through grades nine, ten, and eleven was found. It is important to note that these negative correlations are likely the result of the male non-athlete's academic success, as negative correlation coefficients are seen in the males but not in the females. Tables 5 and 6 examine this possibility by separating the males and females in each grade level.

The female-both-semester academic success and the total athletic success are positively correlated but not statistically significant. The only statistically significant correlation coefficient was during second semester for tenth grade JVF. No trend is noticed.

The non-athlete male-both-semester academic success and the total athletic success are negatively correlated but not statistically significant for the ninth, tenth, and eleventh grades; and positively correlated during the twelfth grade. A trend of increasingly negative correlations during the ninth, tenth, and eleventh grades is noted only in VF and in JVB. In VB and JVF there is a sharp increase in significance from the ninth to tenth grade, but then a drop in the eleventh grade. The trend 
TABLE 5

CORRELATION BETWEEN ATHLETIC SUCCESS AND ACADEMIC SUCCESS OF ALL MALE NON-ATHLETES BY GRADE LEVEL

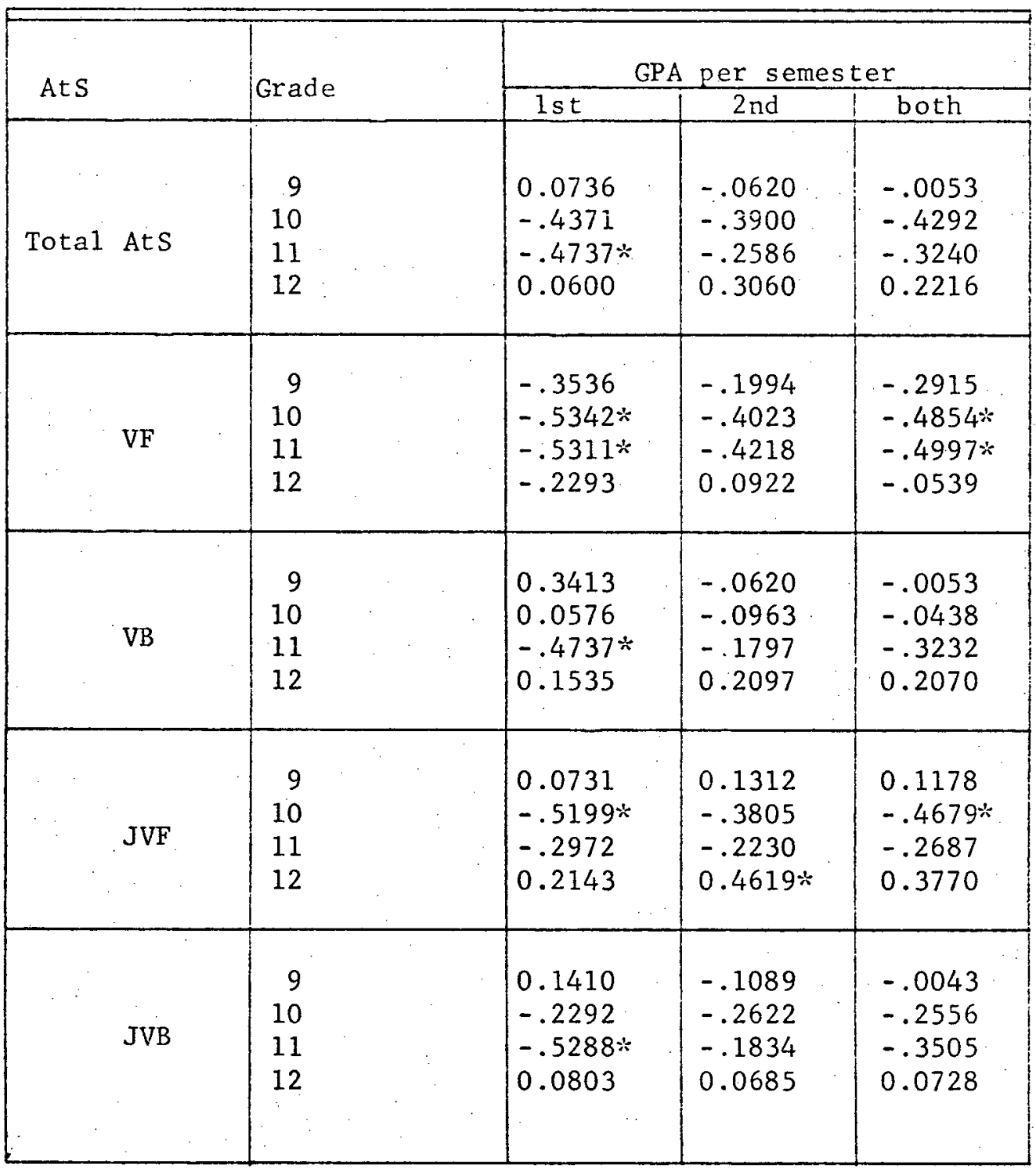

$\star p<.05$ 
TABLE 6

CORRELATION BETWEEN ATHLETIC SUCCESS AND ACADEMIC SUCCESS

OF ALI FEMALES BY GRADE LEVEL

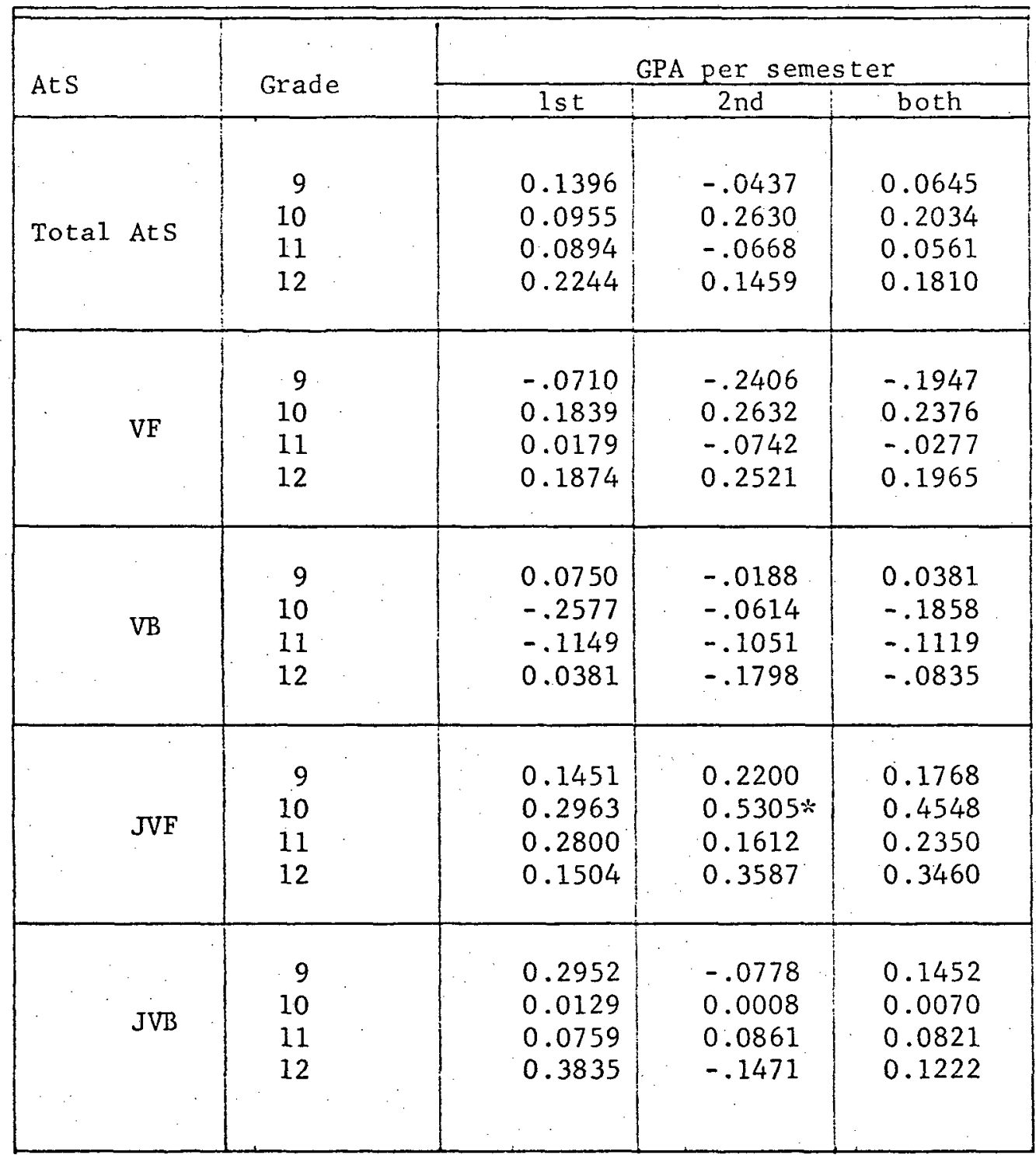

$\therefore p<.05$ 
found in the non-athlete population was due to a combination of the male and female coefficients. The tenth grade-both-semester-female-total AtS correlation coefficient was sufficiently positive so that when combined with the tenth grade-both-semester-male-total Ats correlation coefficient, the resultant non-athlete correlation coefficient was such that it fit in the trend.

Among the non-athlete males, statistically significant correlations are found in the tenth, eleventh, and twelfth grades.

In the tenth grade statistically significant negative correlations are found for varsity and junior varsity football during the first and both-semester. The correlations during the second semester were high but statistical significance was not reached. Here again a possible explanation for these negative correlation coefficients could be an emphasis on athletica1ly orientated behavior during winning seasons, and an emphasis on academic behavior during losing seasons.

In the eleventh grade five statistically significant negative correlation coefficients are found. Here for the first time the correlations between academic success and varsity and junior varsity basketball success were statistically significant. This significance was reached only during the first semester.

In the twelfth grade most of the coefficients are again positive and one reaches statistical significance. The significant correlation is between second semester academic success and junior varsity athletic success. No explanation is offered as one would expect a significant first semester correlation in football if there was a significant second semester correlation. 
The general trend of an abrupt shift from negative to positive coefficients in the twelfth grade is found in the male coefficients only. 
Recently the Berrien Springs Senior High School Board members voted to transfer from one interscholastic league to another. Berrien Springs had been having very poor athletic success. The faculty and administration felt that always losing was having a demoralizing effect on the entire school body; which was carrying over into their academic success.

This paper examines the possibility of there being a relationship between academic success and athletic success. Group grade point averages were calculated for students attending the Berrien Springs Senior High School. These were examined for correlation with the athletic success of varsity and junior varsity basketball and footba11 over a twenty year period. The analysis involved calculating the Pearson product-moment correlation coefficient and testing it for significance.

\section{Summary of Data}

Looking at the total athletic success, no statistically significant correlations between athletic success and academic success were found for the athletes. There was, however, a statistically significant positive correlation between varsity football success and the academic success of the athletes. Athletic success was otherwise not significantly positively correlated with the academic success of the other team members. 
In junior varsity football a non-significant negative correlation was found.

In examining the total athletic success and the academic success of non-athletes, no statistically significant correlation coefficients were found. Many of these correlations were unexpectedly negative. These negative correlations followed a trend through the ninth, tenth, and eleventh grades of becoming more negative. In the twelfth grade the correlations suddenly became positive.

When correlating the total athletic success with the academic success of females and non-athlete males separately; no statistically significant correlations were found. The male correlations were negative, however, and the female correlations were positive.

When examining the athletic success and the academic success of males and females separately in each grade level, it was found that the trend noticed in the ninth, tenth, and eleventh grades was attributable to the combination of the male and female scores, as it was not noticed in either the male or female total Ats correlations. The trend, however, almost reached significance for male-VF-both-semester coefficients. In the twelfth grade the correlations become positive, but only one was statistically significant.

Hypothesis A: Among athletes there is a positive correlation between athletic success and academic success. This hypothesis was not supported when considering total AtS. When only the athletic success of varsity football was examined, however, varsity football success was found to be statistically significantly correlated with academic success.

Hypothesis $\dot{B}$ : Among non-athletes there is a positive correlation between athletic success and academic success. This hypothesis was not 
supported when considering all of the non-participants. When the nonparticipants were considered as male and female groups in each grade level ten significant correlations were found. Nine of these were for males and one was for females. Of the nine statistically significant male correlation coefficients, eight were negative. These occurred in the tenth and eleventh grades. The one statistically significant positive correlation occurred in the twelfth grade.

The one statistically significant female correlation was found between tenth grade second semester athletic success and JVF success. Hypothesis C: Among non-athletes the higher the grade level the greater the correlation between athletic success and academic success. This hypothesis was not supported. A slight trend was noticed, however, of increasingly negative correlations through grades nine, ten, and eleven, and then a abrupt change towards positive correlations in the twelfth grade. The coefficients effecting this trend most nearly reached statistical significance for correlations between VF success and the bothsemester academic success of the males.

Hypothesis D: Among non-athletes the correlation between athletic success and academic success is greater for males than for females. This hypothesis was not supported. In general correlation coefficients for males tended to be negative, and for females positive. When examining the coefficients for all males and all females, the only statistical significance was between male academic success and first semester VF success.

\section{Conclusions}

Athletic success expectancy may be generalized to academic success for varsity football players. However, because significant cor- 
relations were also found during second semester, it would seem more likely that the correlation represents a relationship in the opposite direction, that is, academically successful athletes perform better athletically.

Because few significant correlations were found between the athletic success and academic success of the non-athletes, there is probably no relationship. A slight trend was noted among non-athletes toward more significantly negatively correlation coefficients during the ninth, tenth, and eleventh grades. The coefficients effecting this trend were statistically insignificant for non-athletes as a group, but between the both-semester academic success of males and VF success it approached statistical significance.

The finding of statistically significant positive coefficients between varsity football success and the academic success of these athletes could possibly suggest that varsity football success expectancy is transferring to the dcademic success of these athletes. Other coefficients between athletic success and the academic success of athletes were not significant indicating that probably no transfer of expectancy took place.

The finding of no statistically significant positive coefficients between athletic success and the academic success of non-athletes indicates that the athletic success expectancy was probably not generalized to nonparticipants.

\section{Implications}

Interscholastic athletic competition probably cannot be condemned or merited because of a possible relationship between athletic success and academic success. 
Because there was a significant correlation between varsity football and the academic success of these athletes, a causative relationship probably exists here. Indications were, however, that this was not a generalization of expectancy relationship, but rather a third factor relative to intelligence, that is, more intelligent athletes perform better academically and athletically.

Changing leagues in Berrien Springs will probably not effect a change in academic success, but more success in athletics could still possibly improve development in some other way, such as mentioned on pages three and four of the related research. That is the participation in sports could possibly have a positive effect on the emotional and social adjustment of participants. 


\section{BIBLIOGRAPHY}

Belk, L.V. "A Comparison of the Academic Achievement of Athletes at South Dakota State College." Science and Medicine of Exercise and Sports. Cited by W. R. Johnson. New York: Harper, 1960.

Berkowitz, Leonard. Aggression: A Social-Psychological Analysis. New York: McGraw-Hi11, 1962.

Berkowitz, Leonard. "Aggressive Cues in Aggressive Behavior and Hostility Catharsis." Psychological Review, LXXI (1964), 104-122.

Chance, J. E. "Generalization of Expectancies Among Functionally Related Behaviors." Journal of Abnormal Social Psychology, XXVII (1959), 228-238.

Cozens, F. W., and Stumpf, Florence. Sports in American Life. Chicago: University of Chicago Press, 1953.

Cranda11, V. J. "Induced Frustration and Punishment-Reward Expectancy in Thematic Apperception Stories." Journal of Abnormal Social Psychology, XV (1951), 400-404.

Ferguson, G. W. "A Comparison of Athletic Grade Point Averages with Those of Non-Athletes with Simular Intelligence Quotients." Science and Medicine of Exercise and Sports. Cited by W. R. Johnson. New York: Harper, 1960.

Feshback, Seymor. "The Catharsis Hypothesis and Some Consequences of Interaction with Aggressive and Neutral Play Objects." Journal of Personality, XXIV (1956), 446-462.

Jessor, R. "The Generalization of Expectancies." Journal of Abnormal Socia1 Psychology, XLIV (1954), 196-200.

Jordon, J. W. "Scholastic Aptitude and Scholarship of Athletes." Science and Medicine of Exercise and Sports. Cited by W. R. Johnson. New York: Harper, 1960.

Kenny, D. T. An Experimental Test of the Catharsis Theory of Aggression. Ann Arbor: University Microfilms, 1953.

Kessing, F. M. The South Seas in the Modern World. New York: John Day, 1941 . 
Kremer, M. W. "A Comparison of Scholastic Grades of Athletes and NonAthletes." Science and Medicine of Exercise and Sports. Cited by W. R. Johnson. New York: Harper, 1960.

Kyle, R. "Does Participation in High School Athletics Lower Scholarship." Unpublished M.A. thesis, Ohio State University, 1941.

Layman, E. M. "Aggression in Relation to Play and Sports." Contemporary Psychology of Sport. Edited by G. S. Kenyon. Chicago: The Athletic Institute, 1971.

Riesman, D.; Glazer, N.; Denny, R. The Lonely Crowd. New Haven: Yale University Press, 1950.

Rotter, J. B. Social Learning in Clinica1 Psychology. Englewood Cliffs: N. J.: Prentice Hal1, 1954.

Schuster, S. 0., and Gruen, G. E. "Success and Failure as Determinants of the Performance Predictions of Mentally Retarded and Nonretarded Children." American Journal of Mental Deficiency, LXXVI (September, 1971), 190-196.

Scott, J. P. Aggression. Chicago: University of Chicago Press, 1958.

Stone, A. "The Catharsis Theory of Aggression." Laboratory Bulletine. Laboratory of Social Relations, II (1950), $\overline{9-13 .}$

Summers, H. F. "Athletic Participation and Scholastic Achievement of College Students." Science and Medicine of Exercise and Sports. Cited by W. R. Johnson. New York: Harper, 1960. 